\title{
Deep intracerebral (basal ganglia) haematomas in fatal non-missile head injury in man
}

\author{
J HUME ADAMS, D DOYLE, DI GRAHAM, AUDREY E LAWRENCE, \\ DR MCLELLAN
}

From the University Department of Neuropathology, Institute of Neurological Sciences, Southern General Hospital, Glasgow, Scotland, UK

SUMMARY Deep intracerebral (basal ganglia) haematomas were found post mortem in 63 of 635 fatal non-missile head injuries. In patients with a basal ganglia haematoma, contusions were more severe, there was a reduced incidence of a lucid interval, and there was an increased incidence of road traffic accidents, gliding contusions and diffuse axonal injury than in patients without this type of haematoma. Intracranial haematoma is usually thought to be a secondary event, that is a complication of the original injury, but these results suggest that a deep intracerebral haematoma is a primary event. If a deep intracerebral haematoma is identified on an early CT scan it is likely that the patient has sustained severe diffuse brain damage at the time of injury. In the majority of head injuries damage to blood vessels or axons predominates. In patients with a traumatic deep intracerebral haematoma, it would appear that the deceleration/acceleration forces are such that both axons and blood vessels within the brain are damaged at the time of injury.

Deep intracerebral ("basal ganglia") haematomas in non-missile head injury have long been recognised by pathologists with an interest in head injury ${ }^{1}$ but it is only relatively recently, as a result of the introduction of CT scanning, that it has been possible to recognise other than large deep intracerebral haematomas during life. ${ }^{2}$ This presumably accounts for the relative paucity of publications on this type of haematoma. We are currently undertaking a comprehensive study of brain damage in non-missile head injury ${ }^{3-9}$ and, with the aim of confirming our early impression that a deep intracerebral haematoma is more often than not indicative of the presence of diffuse brain damage and is a primary event rather than a complication of the original injury, we wish to report our observations on 63 patients found to have traumatic deep intracerebral haematoma at necropsy. Our findings are essentially similar to those made by our clinical and neuroradiological colleagues in this institute. ${ }^{2}$

Address for reprint requests: Professor J Hume Adams, Department of Neuropathology, Institute of Neurological Sciences, Southern General Hospital, Glasgow G51 4TF, Scotland. UK.

Received 19 November 1985.

Accepted 5 January 1986

\section{Materials and methods}

During the 15 year period 1968-1982 post-mortem examinations were undertaken in this institute on 635 fatal nonmissile head injuries. There were $497(78 \%)$ males and 138 $(22 \%)$ females; the age range was 9 weeks to 89 years; and the duration of survival ranged from 1 hour to 14 years 3 months. The majority of the injuries were attributable to road traffic accidents $(335 ; 53 \%)$, or to falls $(221 ; 35 \%)$. Of the remaining 79 cases, 31 were assaults, three were crush injuries, 14 were other types of injury, while in the remaining 31 cases the circumstances of the injury were not known. There was a fracture of the skull in $478(75 \%)$ of the cases. The clinical records were assessed with particular reference to any deterioration in the level of consciousness after a lucid interval, defined as whether or not the patient had talked a short time after the injury. ${ }^{10}$

A full post-mortem examination was undertaken in every case and the brain removed by one of us so that a careful note could be made of any extracerebral lesions, such as the tightness of the dura, and the presence of blood in the extradural or subdural spaces. The brains were then suspended in $10 \%$ formol saline for 3-4 weeks before dissection: the cerebral hemispheres were sliced in the coronal plane, the cerebellum at right angles to the folia, and the brain stem horizontally. ${ }^{11}$ Comprehensive histological studies were undertaken in 434 of the 635 cases. These included the preparation of $30 \mu \mathrm{m}$ celloidin sections stained by Nissl's method with cresyl violet and by Woelke's modification of Heidenhain's technique for myelin. Representative blocks were also taken from the cerebral hemispheres, the cerebellum 
and the brain stem for embedding in paraffin wax. Paraffin sections were stained routinely with haemalum and eosin, by the Luxol fast blue/cresyl violet method and by the Palmgren techniques for axons. Other stains were used when they were considered appropriate. Some of the subsequent analyses are based on the 635 cases, but others had to be restricted to the 434 cases since the results were dependent on a comprehensive histological analysis.

A deep intracerebral haematoma was defined as an intracerebral haematoma involving the striatum, the pallidum or the thalamus. Haematomas that had clearly originated in the frontal or temporal lobes were excluded even if they had spread to involve the basal ganglia. A deep intracerebral haematoma was defined as "large" if it was more than $2 \mathrm{~cm}$ in diameter, and "small" if less than $2 \mathrm{~cm}$ in diameter. In all of the 434 cases subjected to a full histological study, conventional surface contusions were assessed quantitatively using the contusion index method. ${ }^{9}$ If there was pressure necrosis in one or both parahippocampal gyri, the patient was deemed to have had a high intracranial pressure during life. ${ }^{12}$

Macroscopic abnormalities in the brains were recorded photographically, and histological abnormalities on a series of line diagrams. All findings were then recorded on a proforma and the data stored in the University of Glasgow's mainframe computer. The patients with and without deep intracerebral haematoma were compared using the chisquare test for associations; and nonparametric WilcoxonMann-Whitney tests were used to assess differences in median values.

\section{Results}

There were 63 patients with deep intracerebral haematomas. These consisted of 49 males and 14 females; the age range was from 2 to 82 years, and the period of survival from 2 hours to 3 months (median survival in the range 24-48 hours). In patients without a deep intracerebral haematoma the median survival time was in the range $2-3$ days. In 43 patients the deep intracerebral haematoma was small and in nine of these the haematomas were bilateral: in 20 patients the deep intracerebral haematoma was large and in one of these patients the haematomas were bilateral. The haematomas occurred most frequently in the region of the thalamus (figs $1 \& 2$ ), but they also occurred more anteriorly (fig 3 ). They often involved the internal capsule, and there were frequently other small haematomas within the brain. In only 11 of the 63 cases $(17.5 \%)$ were there other intracranial haematomas (one extradural, two subdural, four intracerebral and four "burst" lobes), this contrasting with an overall incidence of any type of intracranial haematoma of $60 \%$ in the entire series of 635 cases. There was a fracture of the skull in 45 of the 63 cases $(71 \%)$, this being similar to the overall incidence of a fracture in $75 \%$ of the entire series.

Table 1 shows that there was a high incidence of

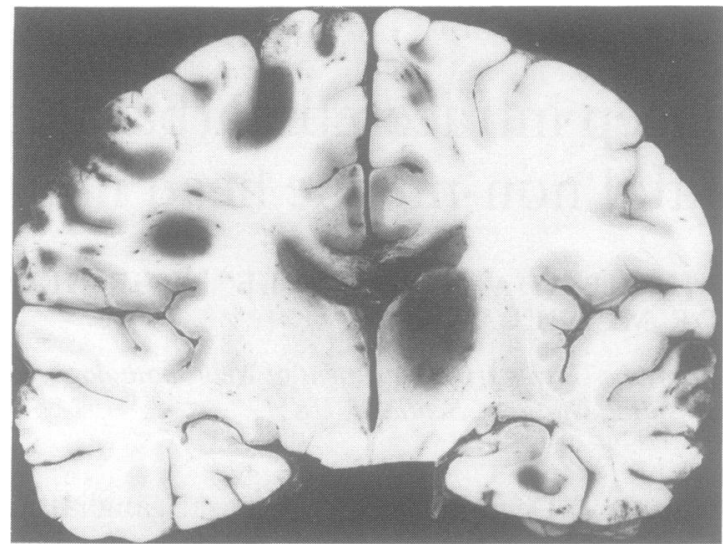

Fig 1 There is a large haematoma centred on the right thalamus. There is also disruption of the corpus callosum, a small haematoma in the deep white matter, and gliding contusions. (Patient died 8 days after a fall).

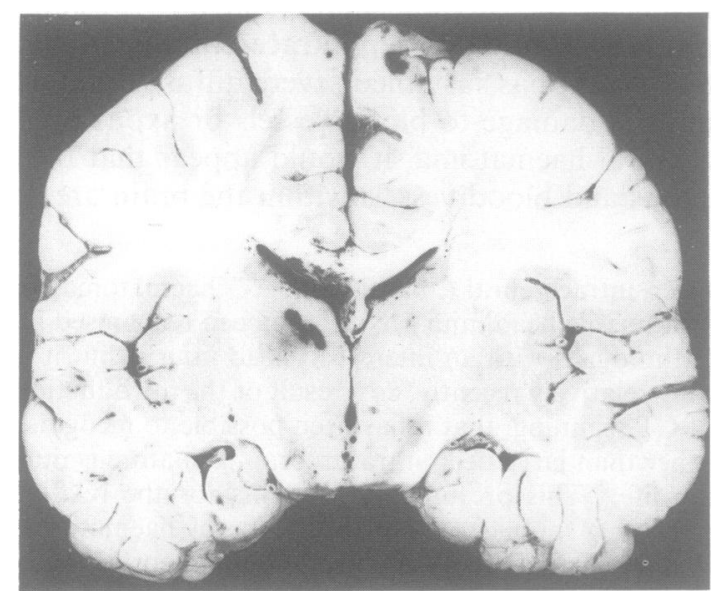

Fig 2 There is a small haematoma in the left thalamus. There is also a haemorrhagic lesion in the corpus callosum and in the fornix (typical of diffuse axonal injury) and gliding contusions. (Patient died 5 days after a road traffic accident).

road traffic accidents in patients with deep intracerebral haematoma. Table 2 shows that conventional surface contusions are more severe in patients with a deep intracerebral haematoma than in patients without this type of haematoma. The relationship between a high intracranial pressure during life and a deep intracerebral haematoma is given in table 3: there was no significant difference between patients with and without a deep intracerebral haematoma. In patients with a deep intracerebral haematoma, however, there was a significantly reduced incidence of lucid interval compared with patients without this type of haematoma (table 4); a higher 


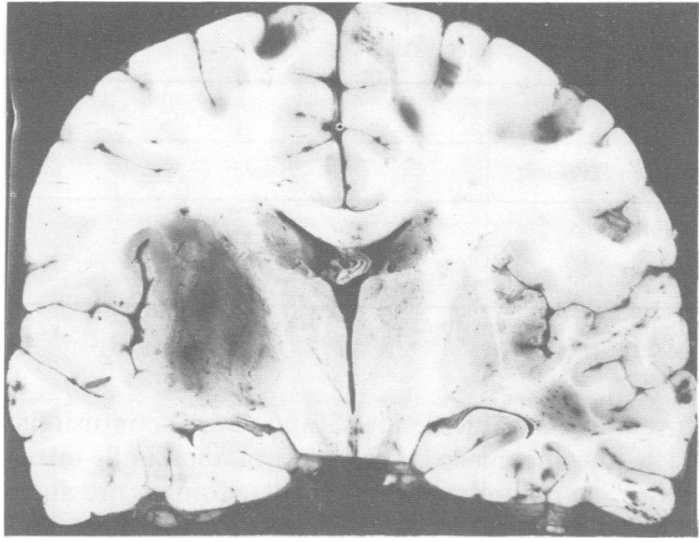

Fig 3 There is a large haematoma centred on the left putamen. There are also gliding contusions and many foci of haemorrhage in the cortex and subcortical white matter. (Patient died 36 hours after a road traffic accident).

incidence of gliding contusions (parasagittal haemorrhagic lesions) than in patients without a deep intracerebral haematoma (table 5, fig 3); and a higher incidence of diffuse axonal injury than in patients without this type of haematoma (table 6).

Table 1 Cause of injury in patients with and without a basal ganglia haematoma $(n=635)$

\begin{tabular}{lll}
\hline & With a haematoma & Without a haematoma \\
\hline Road traffic accident & $43(68 \%)$ & $292(51 \%)$ \\
Fall & $14(22 \%)$ & $208(37 \%)$ \\
Other & $6(10 \%)$ & $72(12 \%)$ \\
\hline
\end{tabular}

Table 2 The total contusion index (TCI) in patients with and without a basal ganglia haematoma $(n=434)$

\begin{tabular}{llll}
\hline & Mean TCI & Median TCI \\
\hline With a haematoma & 22.87 & 23 & $(\mathrm{n}=47)$ \\
Without a haematoma & 18.01 & 16.5 & $(\mathrm{n}=387)$
\end{tabular}

Contusions were more severe in patients with a basal ganglia haematoma $(p<0.05)$.

Table 3 The incidence of a high intracranial pressure (ICP) in patients with and without a basal ganglia haematoma $(B G H)(n=434)$

\begin{tabular}{lllll}
\hline & \multicolumn{3}{l}{ High ICP } \\
\cline { 3 - 5 } & \multicolumn{1}{l}{ Absent } & Present & Total \\
\hline \multirow{2}{*}{ BGH } & Absent & 102 & 285 & 387 \\
& Present & 8 & 39 & 47 \\
& Total & 110 & 324 & 434 \\
\hline
\end{tabular}

There is no significant association in the incidence of a high ICP between patients with and without a BGH.

\section{Discussion}

There is an increasing tendency to classify brain damage resulting from head injury as focal or diffuse. ${ }^{613}$ The principal types of focal damage are conventional surface contusions, the various types of intracranial haematoma, and brain damage secondary to a high intracranial pressure, shift and herniation of the brain. In this era of CT scanning, the clinician usually knows that these types of brain damage are present.

Table 4 The incidence of a lucid interval in patients with and without a deep intracerebral haematoma in fatal non-missile head injury* $(n=614)$

\begin{tabular}{|c|c|c|c|c|}
\hline & & \multicolumn{3}{|c|}{ Lucid interval } \\
\hline & & Absent & Present & Total \\
\hline Basal ganglia haematoma & $\begin{array}{l}\text { Absent } \\
\text { Present } \\
\text { Total }\end{array}$ & $\begin{array}{r}356 \\
52 \\
408\end{array}$ & $\begin{array}{r}201 \\
5 \\
206\end{array}$ & $\begin{array}{r}557 \\
57 \\
614\end{array}$ \\
\hline
\end{tabular}

There is a reduced incidence of a lucid interval in patients with this type of haematoma $(p<0.001)$.

*In 21 of the 614 cases, it was not known if the patient had or had not experienced a lucid interval.

Table 5 The incidence of gliding contusions in patients with and without a deep intracerebral haematoma in fatal non-missile head injury $(n=434)$

\begin{tabular}{|c|c|c|c|c|}
\hline & & \multicolumn{3}{|c|}{ Gliding contusions } \\
\hline & & Absent & Present & Total \\
\hline Basal ganglia haematoma & $\begin{array}{l}\text { Absent } \\
\text { Present } \\
\text { Total }\end{array}$ & $\begin{array}{r}280 \\
18 \\
298\end{array}$ & $\begin{array}{r}107 \\
29 \\
136\end{array}$ & $\begin{array}{r}387 \\
47 \\
434\end{array}$ \\
\hline
\end{tabular}

There is a increased incidence of gliding contusions in patients with deep intracerebral haematoma $(p<0.001)$. 
Table 6 The incidence of diffuse axonal injury in patients with and without a deep intracerebral haematoma in fatal non-missile head injury $(n=434)$

\begin{tabular}{|c|c|c|c|c|}
\hline & & \multicolumn{3}{|c|}{ Diffuse axonal injury } \\
\hline & & Absent & Present & Total \\
\hline Basal ganglia haematoma & $\begin{array}{l}\text { Absent } \\
\text { Present } \\
\text { Total }\end{array}$ & $\begin{array}{r}322 \\
30 \\
352\end{array}$ & $\begin{array}{l}65 \\
17 \\
82\end{array}$ & $\begin{array}{r}387 \\
47 \\
434\end{array}$ \\
\hline
\end{tabular}

There is a increased incidence of diffuse axonal injury in patients with deep intracerebral haematoma (p $<0 \cdot 01)$.

Diffuse brain damage takes the form of diffuse axonal injury, ${ }^{46}$ diffuse hypoxic brain damage, ${ }^{614}$ and diffuse brain swelling. ${ }^{6}$ The clinician may be aware that a patient is suffering from diffuse brain damage but the precise type is more difficult to define during life. Diffuse axonal injury is characterised by focal lesions in the corpus callosum and in the dorsolateral quadrant or quadrants of the rostral brain stem, and by microscopical evidence of diffuse damage to axons. ${ }^{46}$ This type of brain damage has now been produced in non-human primates by inertial (that is non-impact) controlled angular acceleration of the head, ${ }^{15}$ and it is clear that it occurs at the moment of injury, that is it is a primary event. In both man and non-human primates gliding contusions are frequently present in association with diffuse axonal injury. ${ }^{6}$ Diffuse hypoxic brain damage is presumably a secondary event but probably occurs very soon after the injury. Diffuse brain swelling is a wellrecognised event in acute head injury.

The studies undertaken in recent years in the Universities of Pennsylvania and Glasgow based on controlled angular acceleration of the head in nonhuman primates have shed considerable light on the pathogenesis of brain damage brought about by nonmissile head injury in man. ${ }^{315-18}$ These experiments have established that angular acceleration over a very short time through $60^{\circ}$ in the sagittal plane has its principal effect on blood vessels (including the bridging veins) leading to acute subdural haematoma and haemorrhagic contusions on the surface of the brain: on the other hand, slower acceleration, particularly in the lateral plane, produces selective damage to axons (diffuse axonal injury) and traumatic coma in the absence of a high intracranial pressure. In our previous publications on brain damage in non-missile head injury in man, ${ }^{36}$ we have laid particular stress on the distinction between focal brain damage and diffuse axonal injury. In patients with focal brain damage there is a high incidence of falls, fracture of the skull, intracranial haematoma, a lucid interval and a high intracranial pressure; surface contusions, expressed quantitatively, are severe. In contrast, in patients with diffuse axonal injury, there is a high inci- dence of road traffic accidents and gliding contusions, and a low incidence of fracture of the skull, intracranial haematoma and high intracranial pressure, while contusions are less severe. Furthermore, no patient with classic diffuse axonal injury experienced a lucid interval.

The results of the studies undertaken with the University of Pennsylvania model ${ }^{15-18}$ suggest that there are two fundamentally different types of brain injury resulting from acceleration/deceleration forces: injury to blood vessels and injury to axons. An essentially similar conclusion has been reached by Grcevic. ${ }^{19}$ The present analysis suggests that patients with a deep intracerebral haematoma fall into a distinctive category where the original injury has been such that both blood vessels (excluding the bridging veins) and axons have been damaged at the time of injury. This is borne out by the low incidence of a lucid interval, the severity of surface contusions and the high incidence of gliding contusions and diffuse axonal injury in patients with a deep intracerebral haematoma. Of some interest is the observation that only five patients (table 4) experienced a lucid interval. This is strongly suggestive of diffuse brain damage, yet only 17 had the typical structural features of diffuse axonal injury. This raises the possibility that the multiple petechial haemorrhages often observed in individuals who die within minutes of a head injury ${ }^{60}$ may have a similar biomechanical substrate to that which produces deep intracerebral haematomas.

We conclude that deep intracerebral haematoma is a primary event occurring at the moment of injury, and that in general its occurrence is indicative of severe brain damage. This conclusion, based on a study of fatal non-missile head injuries, is in accord with the clinical and radiological studies of our colleagues in the Institute that patients with deep intracerebral haematoma have sustained severe brain damage. $^{2}$

This study was supported by project grant G8007342 from the Medical Research Council. We are grateful to colleagues in the Department of Medical Illustration, Southern General Hospital, Glasgow, for their help. 


\section{References}

${ }^{1}$ Mosberg WH, Lindenberg R. Traumatic hemorrhage from the anterior choroidal artery. $J$ Neurosurg 1959;16:209-21.

${ }^{2}$ Macpherson P, Teasdale E, Dhaker S, Allerdyce G, Galbraith $\mathrm{S}$. The significance of traumatic haematoma in the region of the basal ganglia. $J$ Neurol Neurosurg Psychiatry 1986;49:29-34.

${ }^{3}$ Adams JH, Gennarelli TA, Graham DI. Brain damage in non-missile head injury: observations in man and subhuman primates. In: Smith WT, Cavanagh JB, eds. $R e$ cent Advances in Neuropathology, 2. Edinburgh: Churchill Livingstone, 1982:165-90.

${ }^{4}$ Adams JH, Graham DI, Murray LS, Scott G. Diffuse axonal injury due to non-missile head injury in humans: an analysis of 45 cases. Ann Neurol 1982;12:557-63

${ }^{5}$ Graham DI, McLellan D, Adams JH, Doyle D, Kerr A, Murray LS. The neuropathology of the vegetative state and severe disability after non-missile head injury. Acta Neurochir Suppl 32 1983:65-67.

${ }^{6}$ Adams JH, Graham DI. Diffuse brain damage in nonmissile head injury. In: Anthony PP, MacSween RNM, eds. Recent Advances in Histopathology, 12. Edinburgh: Churchill Livingstone, 1984:241-87.

${ }^{7}$ Adams JH, Doyle D, Graham DI, Lawrence AE, McLellan DR. Diffuse axonal injury in head injuries caused by a fall. Lancet 1984;ii:1420-2.

${ }^{8}$ Adams JH, Doyle D, Graham DI, Lawrence AE, McLellan DR. Microscopic diffuse axonal damage in cases of head injury. Med Sci Law 1985;25:265-9.

${ }^{9}$ Adams JH, Doyle D, Graham DI, et al. The contusion index: a reappraisal in human and experimental nonmissile head injury. Neuropath Appl Neurobiol 1985;11:299-308.

${ }^{10}$ Reilly PL, Graham DI, Adams JH, Jennett B. Patients with head injury who talk and die. Lancet 1975;2:375-7.

${ }^{11}$ Adams JH, Murray MF. Atlas of Post-Mortem Tech- niques in Neuropathology. Cambridge: Cambridge University Press, 1982.

${ }^{12}$ Adams JH, Graham DI. The relationship between ventricular fluid pressure and the neuropathology of raised intracranial pressure. Neuropath Appl Neurobiol 1976;2:323-32.

${ }^{13}$ Gennarelli TA, Spielman GM, Langfitt TW, Gildenberg PL, Harrington T, Jane JA, et al. Influence of the type of intracranial lesion on outcome from severe head injury. $J$ Neurosurg 1982;56:26-36.

${ }^{14}$ Graham DI, Adams JH, Doyle D. Ischaemic brain damage in fatal non-missile head injuries. $J$ Neurol $\mathrm{Sci}$ 1978;39:213-34.

${ }^{15}$ Gennarelli TA, Thibault LE, Adams JH, Graham DI, Thompson CJ, Marcincin RP. Diffuse axonal injury and traumatic coma in the primate. Ann Neurol 1982;12:564-74.

${ }^{16}$ Adams JH, Graham DI, Gennarelli TA. Head injury in man and experimental animals: neuropathology. Acta Neurochir Suppl 32 1983:15-30.

${ }^{17}$ Adams JH, Graham DI, Gennarelli TA. Contemporary neuropathological considerations regarding brain damage in head injury. In: Becker DP, and Povlishock JT, eds. Central Nervous System Trauma Status Report. Washington, National Institute of Neurological and Communicative Disorders and Stroke, National Institutes of Health, 1985:65-77.

${ }^{18}$ Gennarelli TA. Head injury in man and experimental animals-clinical aspects. Acta Neurochir Suppl 32 1983:1-13.

${ }^{19}$ Grcevic N. Topography and pathogenic mechanisms of lesions in "inner cerebral trauma". Red Jug Akad Znan Unig Od Med Nauke 1982;402/18:265-331.

${ }^{20}$ Tomlinson BE. Brain-stem lesions after head injury. In: Sevitt S, and Stoner HB, eds. The Pathology of Trauma. $J$ Clin Pathol Suppl. (Royal College of Pathologists) 1970;4:154-65. 